Jul 1st, 12:00 AM

\title{
A spatial decision support system for the optimal environmental reclamation of open-pit coal mines in Greece
}

F. Pavloudakis

M. Galetakis

Ch Roumpos

Follow this and additional works at: https://scholarsarchive.byu.edu/iemssconference

Pavloudakis, F.; Galetakis, M.; and Roumpos, Ch, "A spatial decision support system for the optimal environmental reclamation of open-pit coal mines in Greece" (2008). International Congress on Environmental Modelling and Software. 270.

https://scholarsarchive.byu.edu/iemssconference/2008/all/270

This Event is brought to you for free and open access by the Civil and Environmental Engineering at BYU ScholarsArchive. It has been accepted for inclusion in International Congress on Environmental Modelling and Software by an authorized administrator of BYU ScholarsArchive. For more information, please contact scholarsarchive@byu.edu, ellen_amatangelo@byu.edu. 


\title{
A spatial decision support system for the optimal environmental reclamation of open-pit coal mines in Greece
}

\author{
Dr. F. Pavloudakis ${ }^{\mathrm{a}}, \underline{\text { Dr. M. Galetakis }}{ }^{\mathrm{b}}$ and Dr. Ch. Roumpos ${ }^{\mathrm{a}}$ \\ ${ }^{a}$ Public Power Corporation of Greece - Mines Division. \\ Kifisou \& Dirachiou 89, 10443 Sepolia, Athens - Greece. \\ ${ }^{b}$ Technical University of Crete - Department of Mineral Resources Engineering. University \\ Campus, Akrotiri, 73100 Chania - Greece. (galetaki@mred.tuc.gr)
}

\begin{abstract}
Mine reclamation is an integral part of the mineral development process. The selection of land uses after the mine closure is a difficult decision, which is complicated further due to the variety of parameters that must be taken into account trying to provide the local community with a viable development plan. Conventional methods used for reclamation planning are characterised by the lack of data integration and by timeconsuming analysis. In this study we propose a spatial decision-support system (SDSS) that minimizes these problems, as data integration and analysis are offered within one computerized environment. A geographical information system and multi-criteria decisionmaking methods, based on binary integer linear programming models, have been integrated to select the appropriate land use in different parts of a post-mining area taking into account social, technical, economic, environmental and safety criteria. The proposed SDSS was used for the selection of the optimal landscape reclamation strategy of the Amynteon lignite surface mine located at West Macedonia Lignite Centre, Northern Greece. Based on the developed mine maps, the model variables are assessed and incorporated into the objective optimization function. Emphasis is placed on the spatial diversification of the model variables. The application demonstrates that the decision-support system allows the mining company to determine in an efficient way the specific land use (agricultural land, forest, recreational area and industrial zone) that is considered the most suitable for every part of the study area.
\end{abstract}

Keywords: mining; reclamation; decision support systems; linear programming;GIS.

\section{INTRODUCTION}

Coal deposits exploitation in open-pits is an activity that impacts adversely the environment. No matter the effectiveness of the environmental management practices that are applied by the mine operator, often, these mining activities led to severe environmental degradation just because of their enormous size. Moreover, these activities last for many decades. Otherwise there is not enough pay-back time for the capital invested for mine development. As a consequence, mining activities affect irreversibly the local communities, which adjust their life-style and depend their economic prosperity on the development plans of the mining company [Pavloudakis et al., 2004, 2006].

In this context, the selection of land uses after the mine closure is a difficult decision, which is complicated further due to the variety of parameters that must be taken into account trying to provide the local community with a viable development plan. Many of those decision-making parameters are characterized by spatial diversification. For instance, parameters such as geological structure, hydrological pattern, land morphology, slopes stability and orientation, distance from public utilities, accessibility from existing roads, etc. are considered critical for deciding for the development of agricultural, recreational or residential activities in a rehabilitated mining area. 
Conventional methods used for reclamation planning and design are characterised by the lack of data integration and by time-consuming analysis. Therefore, the main objective of the present paper is to demonstrate how Spatial Decision-Support System (SDSS) minimize these problems providing a single computer platform of data integration and analysis: a geographical information system (GIS) and a multi-criteria decision-making (MCDM) tool are combined to select the appropriate land use in different parts of a post-mining area taking into account technical, economic, environmental and safety criteria. Since SDSS aided reclamation planning and design will be time efficient, several reclamation strategies can be generated and evaluated with the use of different priority schemes offering significant help in the selection of the optimal land reclamation method [Fortner et al., 2004, Giove et al., 2007].

\section{GIS AND MULTICRITERIA DECISION ANALYSIS}

Environmental decisions are often complex, multi-faceted, and involve many different stakeholders with different priorities or objectives. Moreover, environmental decisions typically draw upon multidisciplinary knowledge bases, incorporating natural, physical, and social sciences, medicine, politics, and ethics. This fact, and the tendency of environmental issues to involve shared resources and broad constituencies, means that group decision processes are called for. For environmental management projects, decision makers may currently receive four types of technical input: modelling/monitoring, risk analysis, cost or cost-benefit analysis, and stakeholders' preferences. Every technique incorporates information coming in different forms. While modelling and monitoring results are usually presented as quantitative estimates, risk assessment and cost-benefit analyses allow a higher degree of qualitative judgment by the project team. [McDaniels et al., 1999; Kiker et al., 2005; Linkov et al., 2004]. The common purpose of these diverse methods is to be able to evaluate and choose among alternatives based on multiple criteria using systematic analysis that overcomes the observed limitations of unstructured individual and group decision-making. Some techniques rank options, some identify a single optimal alternative, some provide an incomplete ranking, and others differentiate between acceptable and unacceptable alternatives [Guitouni and Martel, 1998; Diwekar and Small, 2002; Linkov et al., 2004].

Focusing on Multi-Criteria Decision Analysis (MCDA) models, these allow for more accurate representation of decision problems, by accounting for several objectives. These often exhibit a hierarchical structure. The highest level represents the broad overall objectives (e.g., improving the soil fertility in reclaimed mine areas). They may be broken down into more operational and practically assessed lower level objectives (e.g., increasing the content of nutrients, enhancing the mechanical properties). Sometimes only proxies are available (e.g., if the objective is to enhance recreation opportunities, the number of recreation days can be used). In MCDA models, value judgments may be required in choosing the proper attribute, but measurement does not have to be in monetary terms, like in the case of using cost-benefit analysis as a single criterion. Moreover, a critical advantage of MCDA modelling in group decisions is the capacity for calling attention to similarities or potential areas of conflict between stakeholders with different views, which results in a more complete understanding of the values held by others [Kiker et al., 2005].

The conceptual idea, on which most of GIS-based multicriteria analyses rely, is to use the GIS capabilities to prepare an adequate platform for using multicriteria methods. The GISbased multicriteria analysis starts with the problem identification, where the capabilities of the GIS are used to define the set of feasible alternatives and the set of criteria. Then, the overlay procedures are used in order to reduce an initially rich set of alternatives into a small number of alternatives which are easily evaluated by using a multicriteria method [Chakhar and Martel, 2003; Chakhar and Mousseau, 2007]. The most common integrations of GIS with MCDM systems include the integration with expert systems and mathematical models such as linear programming (LP). Guerra and Lewis [2002] have developed a spatial optimisation model using GIS and an external linear programming solver for selecting the site of a reserve for reintroducing wildlife species. Moreover, McCarthy et al. [2008] have integrated GIS and an expert system platform for processing large amounts of 
spatial data deriving from sensors for making decisions relevant to slopes stability and geotechnical hazards. Other examples of SDSS in land use management and risk analysis are provided by Chen et al. [2001] and Roetter et al. [2005].

The optimization model (a GIS in combination with a LP model), presented in the following paragraphs is capable of supporting decisions about land uses that must be developed in different parts of an area affected by surface mining operations. For this purpose, it employs numerical scores to communicate the benefits resulting from one option in comparison to the others, based on a single scale. Aggregated scores are developed from the performance of alternative land uses with respect to all individual criteria. Individual scores are averaged using a weighting mechanism which favours the most important criteria.

\section{DESCRIPTION OF THE STUDY AREA}

The study area is located in Ptolemais lignite-bearing basin, in the Region of West Macedonia, Northern Greece. In particular, the lignite deposit of Amynteon extends over an area of $14 \mathrm{~km}^{2}$. The surface mine that has been developed and operates in this area during the last 25 years occupies currently 6,000 ha and supplies with lignite a thermal power plant with an installed capacity of 600MW. The Amynteon mine pit is developed from a depth of $40-50 \mathrm{~m}$, in the eastern boxcut area, and reaches the depth of $250 \mathrm{~m}$ in the central section of the western rim slope and the depth of $180 \mathrm{~m}$ in the area of the southern rim slope. After the mine closure, the final pit will be filled up with water. For stability reasons, the inclinations of the final pit slopes are planned to be 1:5 on the excavation side and 1:7 on the waste dumping side. These values will be probably reviewed after a thorough investigation of the type of earth materials that will be dumped in the wave-attack zone of the artificial lake.

The mine and the power plant are surrounded by a relatively flat agricultural area, with an extensive network of irrigation channels and three lakes: Himaditis, Petron and Vegoritis. Some areas nearby the water bodies are controlled by laws and regulations relevant to the preservation of wildlife and of sensitive environmental components, which set specific restrictions regarding the development of human activities. Moreover, in the vicinity of the mine there are several villages. According to the National Regulation of Mining and Quarries Works, mining activities must keep a clearance of 250m from residential areas.

\subsection{Environmental aspects}

Open-pit lignite mines are complex operations that can affect numerous environmental constituents in various ways. Pavloudakis and Roumpos [2004] have described the "processes" and "waste streams" that are considered to have greater potential of causing environmental damage in lignite surface mining areas. The resulting impacts can be classified to those related to the mine operation and last until the mine closure, such as the deterioration of ambient air quality due to dust emissions, and those of permanent character unless proper land reclamations measures are applied. In the latter category the following impacts are included: alteration of morphology, changes in hydrological pattern, loss of wildlife habitat, degradation of landscape value, reduction of property value, loss of topsoil and loss of agricultural land. The above impacts must take increased interest if the planning of land uses for the post-mining era is in question.

\subsection{Social and economic aspects}

The development of every large-scale mining project aims at creation of wealth and employment, boosting, in this way, the National, Regional and local economies. Nevertheless, there are many adverse socioeconomic impacts that can violate the quality standards for the communities located in the vicinity of mining sites. These impacts can be summarised in the following three broad categories: changes in economic activities, 
occupation of land for a long-period (usually many decades) and limited access to public utilities. For a mine operator, the development of public relations on the basis of mutual respect and understanding with local authorities is a critical parameter for the acceptance of a surface mining activity and reclamation plan. For this reason, mining companies must provide every stakeholder with all information necessary to explain not only the expected environmental impacts but also the benefits resulting for the local communities.

\subsection{Planning for the post-mining period}

According to the environmental permits that regulate the mining operations in the study area, the mine operator is obliged to carry out and finance land reclamations works to a certain extent that is described in the permits and in supplementary studies. However, these works are possible to be proved inadequate for assuring the economic prosperity of the local communities. Therefore, from the early stages of the land reclamation works, the local authorities must agree with the mine operator on a development strategy, which will be facilitated by all mine-land reclamation activities. To this extent, the proposed SDSS model provides to the public, local authorities and experts the possibility of expressing their opinions in two ways: (i) setting restrictions or presenting their preferences regarding the percentage of the coverage of the study area from every land use, and (ii) proposing specific land uses for specific parts of the study area.

\section{METHODOLOGY}

\subsection{Information sources}

Spatial information was obtained mainly from an orthophotomap (Figure 1). For the purposes of land reclamation planning and co-operation with local and supervisory authorities the orthophotomap is printed in scales of 1:15,000 and 1:32,000 allowing positional accuracy down to $7.5 \mathrm{~m}$. Spatial information was also obtained from maps and pictures that represent parts of the study area prior to the mine development, as well as from plots and sections produced from the mining company, determining the boundaries and the inclination of the final slopes of the pit and the waste heaps at the time of mine closure. Moreover, other sources of information that were used are:

- meetings and discussions with experts, citizens and representatives of local authorities

- the terms and conditions of the Amynteon mine environmental permits

- legal documents (e.g. National Regulation of Mining \& Quarrying Works)

- laboratory analyses carried out for determining the fertility and other properties of the soil, which are closely related to the possibility of developing certain land uses.

Additional information deriving from monitoring of several geohydrological, water quality and wildlife parameters can be included in the system as long as reliable data bases will be available.

\subsection{Selection of criteria}

Once the problem has been delineated and the information sources have been identified, the spatial multi-criteria analysis focuses on the selection of criteria. This is a process that depends on the characteristics of the decision problem, even though there are some techniques which facilitate the choice of the parameters which influence decision making [Keeney \& Raiffa, 1993]. In the case of Amynteon lignite mining area the determination of land uses is based on a multi stage procedure and a series of criteria presented in Figure 2. The criteria are classified into those showing spatial variation and those with no spatial character. In step 1, which includes all these criteria with no spatial character, priorities and limitations are declared in a way that affects the formulation of the ultimate goal of the modelling procedure. Furthermore, the spatial analysis criteria are different from the criteria of step 2, which are used for selecting one of the following land uses: 'agriculture land', 'forest', 'recreational area' and 'industrial zone', and the criteria of step 3, which are relevant to the suitability of soil for supporting the rapid development of a vegetative cover and are used for determining the type of trees or the type of cultivation, in case that the 
selected land use is 'forest' or 'agricultural land' respectively.

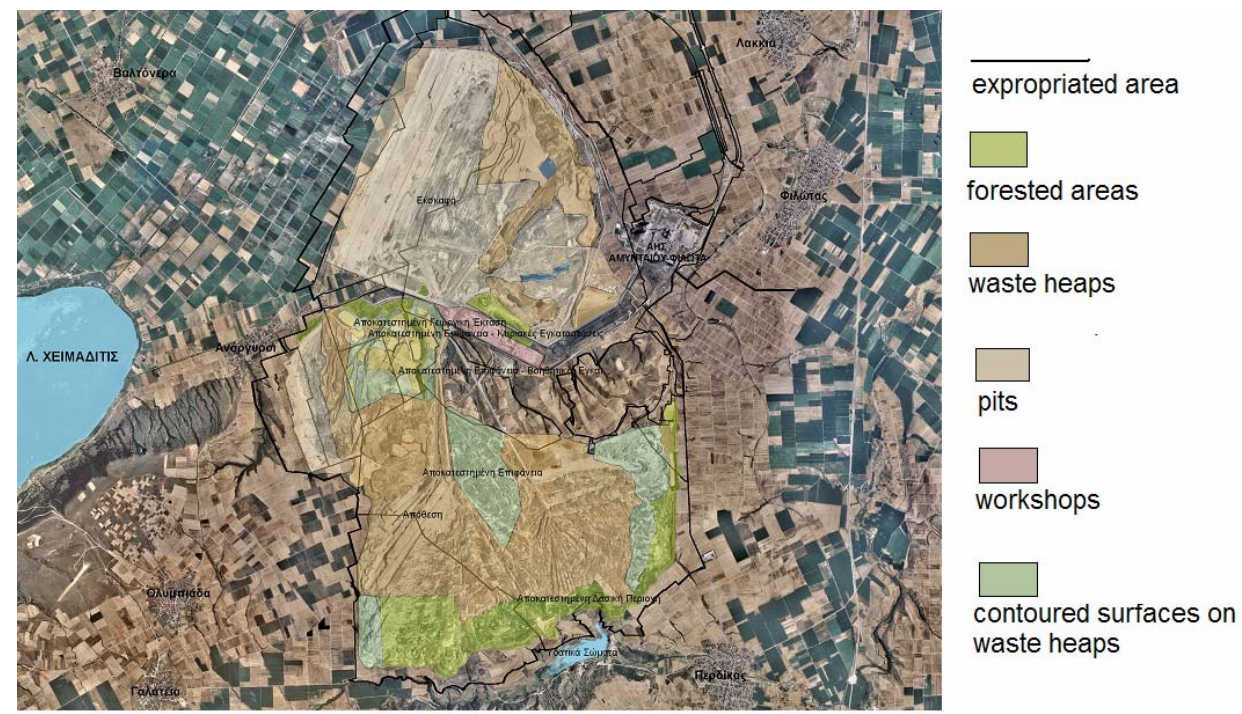

Figure 1. Orthophotomap of the greater area of Amynteon mine

\subsection{Ranking of criteria}

In the examined case the criteria do not have similar importance. To stress their differences, each criterion must be assigned to a specific weight that corresponds to its relative significance. For this purpose several methods are offered. The most popular are the 'ranking', 'rating', 'pairwise comparison' and 'trade-off' methods [Hair et al., 1995]. For the particular model and for the criteria used in the first step, the ranking method was considered as the most suitable. Starting from the most important factor, the decided rank was: 1. legal restrictions, 2. public opinion, 3. experts opinion, 4. potential of wealth creation, 5. cost, and 6. former land uses. Regarding the spatial criteria, these were assigned specific weights using again the ranking method. For the criteria of Step 2 the rank is: 1. slope, 2. soil fertility, 3. proximity to lakes, 4. proximity to archaeological sites, 5 . proximity to villages, while for the criteria of Step 3 the rank is: 1. irrigation infrastructures, 2. $\mathrm{pH}$, acidity, alkalinity, 3. nutrients concentration, 4. mechanical properties, 5. metals concentration. It worth to be noticed that the criteria of slope, proximity to lakes and metals concentrations are closely related to legal or safety constrains, which can be prohibitive for certain land uses. For this reason, these criteria must be distinguished from others, which may influence the model either positively or negatively, depending on their values. For instance, if the slope of a reclaimed surface is higher than 1:5 this surface is unsuitable for any other land use but reforestation, while if an area is within the preservation zone that surrounds a lake (e.g. zone of "Natura 2000") is unsuitable for any other land use but reforestation and low-intensity agricultural use.

\subsection{Spatial analysis}

The spatial analysis of the examined decision-making problem starts with the definition of restrictions and preferences regarding the land uses of the reclaimed mine area. For instance, a preference can be expressed as: 'at least 1,000 ha of agricultural land must be developed', while a restriction as: 'the industrial zone will be less than 500 ha'. In case of an opposite opinion about land uses, the one that will be taken into account will be chosen based on the rank of importance presented in paragraph 5.3 for the criteria of step 1 . Then, the study area is divided into small squares. The dimensions of those squares can be decided taking into account the size of the study area and the variability of the examined criteria. For assessing the fertility of the reclaimed mine surfaces four soil samples per hectare are suggested by the literature [Hansen, 1996]. So, the square dimensions can be $50 \mathrm{~m} \times 50 \mathrm{~m}$ unless this choice requires enormous sampling, analytical and data processing work. 


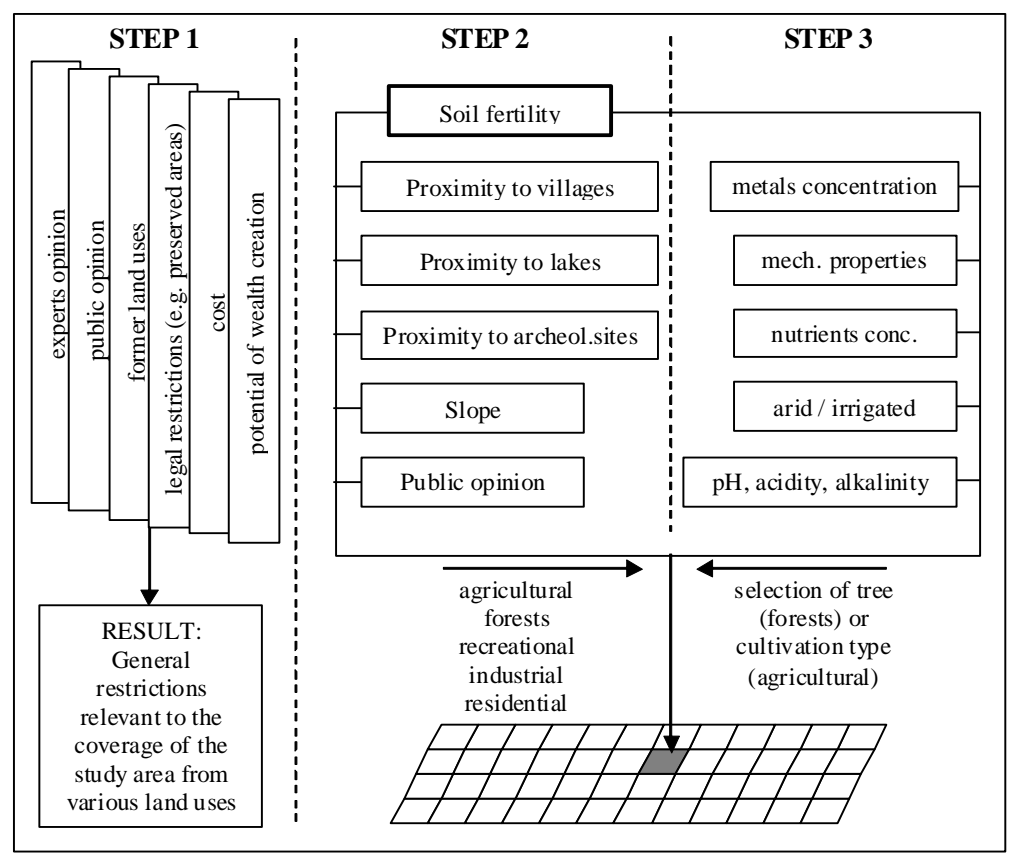

Figure 2. Criteria incorporated at the successive steps of the decision-making procedure.

For every square of the reclaimed mine land, the most suitable land use is proposed by applying the following rating scale: $0=$ low, $1=$ medium, $2=$ high. Table 1 presents a matrix with the values of the step 2 criteria which are considered the optimum ones for the selection of each one of the four alternative land uses. Using the above presented optimum values, for each square-element of the study area and for each criterion the absolute value of the deviation of the actual rate from the optimum one is calculated (Table 2). Then, the sum of deviations of the five criteria are calculated for each land use and the land uses are ranked starting from the one that scores the least sum of deviations from the optimum criteria values. In case of equal scores for two or more land uses, the ranking procedure takes into account the criteria ranking of step 2 presented in the paragraph 4.3. The final step of the proposed SDSS regards the review of the above-selected land uses for all square elements of the study area in a way that meets the limitations set in step 1. For this purpose, the decision-variables are defined as shown in the Table 3, which derives from Table 2 by ranking the four alternatives land uses according to their sum of deviations from the optimum criteria values.

Table 1. Optimum criteria values for the selection of the four alternative land uses.

\begin{tabular}{lcccc}
\hline Criteria & $\begin{array}{c}\text { Agricultural } \\
\text { land }\end{array}$ & Forest & $\begin{array}{c}\text { Recreational } \\
\text { area }\end{array}$ & $\begin{array}{c}\text { Industrial } \\
\text { zone }\end{array}$ \\
\hline Slope & 0 & 1 or 2 & 0 & 0 \\
Soil fertility & 2 & 0 or 1 & 1 or 2 & 0 \\
Proximity to lakes & 0 or 1 & 0 or 1 or 2 & 2 & 0 \\
Proximity to archaeological sites & 0 or 1 & 0 or 1 or 2 & 2 & 0 \\
Proximity to villages & 0 or 1 & 0 or 1 or 2 & 2 & 0 \\
\hline
\end{tabular}

Table 2. Deviation from the preferable land uses' criteria values (best rates in bold)

\begin{tabular}{ccccc}
\hline \multirow{2}{*}{ Squares $(\mathrm{i}, \mathrm{j})$} & $\begin{array}{c}\text { Agricultural } \\
\text { land }\end{array}$ & $\begin{array}{c}\text { Forest } \\
\text { Recreational } \\
\text { area }\end{array}$ & $\begin{array}{c}\text { Industrial } \\
\text { zone }\end{array}$ \\
\cline { 2 - 5 } & \multicolumn{2}{c}{ Deviation from the preferable criteria values } \\
\hline 0,0 & $\mathbf{0}$ & 1 & 6 & 3 \\
0,1 & 3 & $\mathbf{1}$ & 5 & 4 \\
0,2 & 2 & 1 & $\mathbf{0}$ & 3 \\
$\ldots$ & $\ldots$ & $\ldots$ & $\ldots$ & $\ldots$ \\
$\mathrm{n}, \mathrm{m}$ & 2 & 2 & 7 & $\mathbf{0}$ \\
\hline
\end{tabular}


Table 3. Ranking of the four alternative land uses according to their suitability

\begin{tabular}{ccccc}
\hline Squares (i, j) & $\begin{array}{c}\text { Agricultural } \\
\text { land }\end{array}$ & Forest & $\begin{array}{c}\text { Recreational } \\
\text { area }\end{array}$ & $\begin{array}{c}\text { Industrial } \\
\text { zone }\end{array}$ \\
\cline { 2 - 5 } 0,0 & $\mathrm{C}_{\mathrm{ij} 1}$ & $\mathrm{C}_{\mathrm{ij} 2}$ & $\mathrm{C}_{\mathrm{ij} 3}$ & $\mathrm{C}_{\mathrm{ij} 4}$ \\
0,1 & $\mathbf{1}$ & 2 & 4 & 3 \\
0,2 & 2 & $\mathbf{1}$ & 4 & 3 \\
$\ldots$ & 3 & 2 & $\mathbf{1}$ & 4 \\
$\mathrm{n}, \mathrm{m}$ & $\ldots$ & $\ldots$ & $\ldots$ & $\ldots$ \\
\hline
\end{tabular}

Based on Table 3, the ranking of land uses of each square (i,j) is possible. For instance means that for the square-element $(0,0)$ the most suitable land use is 'agricultural land'. It is now possible to use a minimization algorithm to find out the optimal land uses combination for all square-elements of the study area (discrete optimisation problem solved by applying binary linear integer programming). The objective function $\mathrm{Z}$ which must to be minimised is as follows:

$\operatorname{MinZ}=\sum_{i=0}^{n} \sum_{j=0}^{m} \sum_{k=1}^{4} \mathrm{C}_{\mathrm{ijk}} \mathrm{X}_{\mathrm{ijk}} \quad \mathrm{X}_{\mathrm{ijk}}=0$ or $1, \forall i=0, \ldots, n, \quad j=0, \ldots, m, \quad k=1, . ., 4$

under the constraints:

$\sum_{k=1}^{4} \mathrm{X}_{\mathrm{ijk}}=1, \forall i=0, \ldots, n, \quad j=0, \ldots, m$

$\sum_{i=1}^{n} \sum_{j=1}^{m} \mathrm{X}_{\mathrm{ij} 1} \leq K \quad \sum_{i=0}^{n} \sum_{j=0}^{m} \mathrm{X}_{\mathrm{ij} 2} \leq L \quad \sum_{i=0}^{n} \sum_{j=0}^{m} \mathrm{X}_{\mathrm{ij} 3} \geq M \quad \sum_{i=0}^{n} \sum_{j=0}^{m} \mathrm{X}_{\mathrm{ij} 4} \leq N$

where, $\mathrm{K}=$ maximum agricultural land area (i.e. max number of square-elements), $\mathrm{L}=$ maximum forest area, $\mathrm{M}=$ minimum recreational area and $\mathrm{N}=$ maximum industrial zone area

The final result of this procedure is illustrated in Figure 3, which refers to a part of the study area.
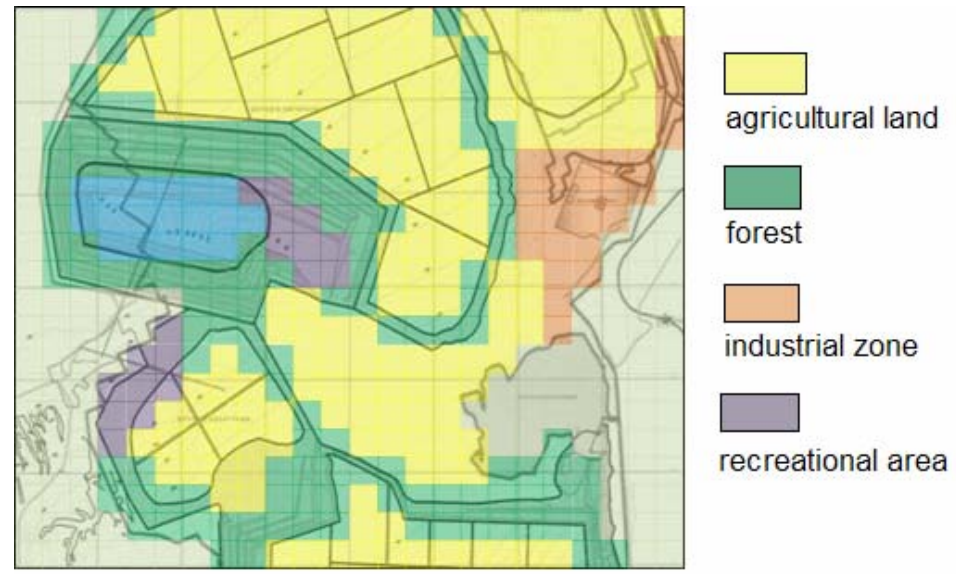

Figure 3: Final proposal regarding land uses in the study area.

\section{CONCLUSIONS}

The primary objective of the study was to facilitate the land use processes, of areas affected by mining, in the presence of multiple and diverse decision criteria using GIS in combination with a LP model. To achieve this, effort focused mainly on the following subobjectives: (i) to use GIS as tool to provide all the necessary data and to visualize the results (ii) to develop a multiple criteria decision support system based on binary integer LP, and (iii) to integrate the LP model and the GIS in a SDSS to facilitate the land use suitability analysis. The application of the developed SDSS in the selection of the optimal landscape reclamation strategy of the Amynteon lignite surface mine located at West 
Macedonia Lignite Center, Northern Greece indicated that the decision-support system allows the mining company to evaluate different reclamation schemes maximizing the long-term sustainability of the broader mining area.

\section{REFERENCES}

Chakhar, S., Martel, J.M., Enhancing geographical information systems capabilities with multi-criteria evaluation functions, "Journal of Geographic Information and Decision Analysis”, Vol. 7(2), 47-71, 2003.

Chakhar, S., Mousseau, V., Multicriteria Spatial Decision Support Systems. In Shashi Shekhar and Hui Xiong (eds.), Encyclopedia of Geographical Information Science. Springer, 2007.

Chen, K., Blong, R., Jacobson, C., MCE-RISK: integrating multicriteria evaluation and GIS for risk decision-making in natural hazards, Environmental Modelling \& Software, 16(4), 387-397, 2001.

Diwekar, U., Small M.J., Process analysis approach to industrial ecology, Chapter 11 in " $A$ Handbook of Industrial Ecology”, R.U. Ayres and L.W. Ayres, eds., Edward Elgar Ltd, Cheltenham, UK, 114-137, 2002.

Fortner A., Smith, D., and Rohrer C., GIS as a prioritization and planning tool in abandoned mine Reclamation, paper presented at Advanced Integration of Geospatial Technologies in mining and Reclamation, Atlanta, December 6-10, 2004.

Giove, S., Agostini P., Critto, A., Semenzin, E., and Marcomini A., Decision support systems for the management of contaminated sites. A Multi-Criteria Approach, Environmental Security in Harbors and Coastal Areas, I. Linkov et al. (eds.), 267-273, 2007.

Guerra, G., Lewis, J., Spatial optimisation and GIS - Locating an optimal habitat for wildlife reintroduction, ArcUser, April-June, 2002.

Guitouni, A., Martel. J.M., Tentative Guidelines to Help Choosing an Appropriate MCDA Method, European Journal Operations Research, Vol. 109, 501-521, 1998.

Hair, J.F., Anderson, R.E., Tatham, R.L. \& Black, W.C., Multivariate Data Analysis with Readings, Prentice Hall, New Jersey, 1995.

Hansen M.M., (edt), Handbook of western reclamation techniques, University of Wyoming \& US Office of Surface Mining, 504pp, 1996.

Keeney, R.L., Raiffa, H., Decisions with Multiple Objectives: Preferences and Value Tradeoffs, Cambridge University Press, Cambridge, 1993.

Kiker, G.A., Bridges, T.S., Varghese, A., Seager, T.P., Linkov, I., Application of multicriteria decision analysis in environmental decision making, Integrated environmental assessment \& management, Vol. 1(2), 95-108, 2005.

Linkov, I., Varghese, A., Jamil, S., Seager, T.P., Kiker, G., Bridges, T., Multi-criteria decision analysis: A framework for structuring remedial decisions at contaminated sites, in Linkov, I. and Ramadan, A. (eds.), "Comparative Risk Assessment and Environmental Decision Making”, Kluwer, 2004, p. 15-54.

McDaniels, T.L., Gregory, R.S., Fieldsm D., Democratizing risk management: Successful public involvement in local water management decisions, Risk Analysis, 19, 497-510, 1999.

McCarthy, J.D., Graniero, P.A., Rozic, S.M., An integrated GIS - expert system framework for live hazard monitoring and detection, Sensors, 8, 830-846, 2008.

Pavloudakis, F. Roumpos, C. Evaluation of land reclamation and environmental protection strategies in open-pit lignite mines, Paper presented at Advances in Mineral Resources Management and Environmental Geotechnology, Chania, Greece, June 9-11, 2004.

Pavloudakis, F., Roumpos C., Sachanidis C. \& Galetakis M., Environmental impacts assessment of surface mining operations: A review of the Greek experience, Paper presented at Mine Planning and Equipment Selection, Torino, Italy, September 22-26, 2006.

Roetter, R.P., Hoanh, C.T., Laborte, A.G., Van Keulen, H., Van Ittersum, M.K., Dreiser, C., Van Diepen, C.A., De Ridder, N., Van Laar, H.H., Integration of Systems Network (SysNet) tools for regional land use scenario analysis in Asia, Environmental Modelling \& Software, 20(3), 291-307, 2005. 